\title{
АКТУАЛЬНЫЕ ТЕНДЕНЦИИ НА РЫНКЕ НЕДВИЖИМОСТИ США
}

\author{
(c) 2020 Гуро Дарья Тимуровна \\ студент экспертизы и управления недвижимостью \\ Сибирский федеральный университет, Россия, Красноярск \\ E-mail: gdt2180@gmail.com \\ (c) 2020 Костылев Петр Николаевич \\ студент экспертизы и управления недвижимостью \\ Сибирский федеральный университет, Россия, Красноярск \\ E-mail: qpeterkosq@gmail.com \\ (c) 2020 Амзаракова Полина Александровна \\ студент экспертизы и управления недвижимостью \\ Сибирский федеральный университет, Россия, Красноярск \\ E-mail: pol.amzarakova@yandex.ru \\ (c) 2020 Лукина Лидия Андреевна \\ студент экспертизы и управления недвижимостью \\ Сибирский федеральный университет, Россия, Красноярск \\ E-mail: lida.lukina.2015@mail.ru \\ (C) 2020 Короткова Светлана Андреевна \\ студент экспертизы и управления недвижимостью \\ Сибирский федеральный университет, Россия, Красноярск \\ E-mail: svetlanna4443@gmail.com
}

В последнее время приобретение недвижимости в США является самым экономическипривлекательным видом вложения денег. Одной из причин является подорожание жизни. В данной статье рассмотрены основные типы недвижимости в США, охарактеризованы главные черты рынка недвижимости в Америке, а также проведен анализ тенденций его развития.

Ключевые слова: недвижимость, инвестиции, рынок недвижимости, США.

Среди разнообразия инвестиций в жилье одним из самых выгодных и финансовоцелесообразных является покупка недвижимости в США. Это обусловлено несколькими причинами. Первая - это выгодная цена на недвижимость в США по сравнению с европейскими странами. Во-вторых, в США гораздо больше места для строительства жилья. В Европе зачастую нет таких больших площадей под строительство, особенно в маленьких городах. При этом качество строительства в Америке не уступает по качеству Европе, а местами даже выигрывает.

Также после ипотечного кризиса в США (2007-2008 гг.) цены на недвижимость значительно упали, став более привлекательными для покупателя. В периоды экономического роста в Калифорнии рост цен на недвижимость составлял всего $10-15 \%$, а в некоторых местах доходил до тридцати. Такая тенденция прослеживалась и в других штатах. Подобная ситуация предположительно может повторится после выхода Америки из экономического спада.

Самыми яркими плюсами покупки недвижимости в США являются - перспективность и стабильность инвестиций. Ведь Америка - одна из самых богатых и развитых стран мира, поэтому риски подобных вложений в США доходят до минимума. Владелец недвижимости в США может сдавать жилье в аренду, перепродать и таким образом получить прибыль. Также владелец может жить в квартире или доме, постепенно занимаясь его благоустройством и отделочными работами. Ведь недвижимость с выполненным ремонтом стоит гораздо больше, да и цены со временем будут расти, а значит можно получить большую выгоду, однажды вложившись в жилье в США.

Ниже мы рассмотрим самые популярные типы недвижимости в США: 
1. «Single Family Home» - это дом, предназначенный для проживания одной семьи. У владельца после покупки появляются три варианта дальнейшего развития событий: он может сделать ремонт, а после продать жилье; сдавать его в аренду; жить в доме и ждать повышения цен, чтобы в будущем продать как можно выгоднее.

Таким образом владелец дома получает широкий спектр экономически-выгодных возможностей, покупая дом в Америке. Не говоря уже о том, что он может просто купить его и жить в молодой и развивающейся стране.

2. «Condo» - это квартира. Владелец подобного жилья имеет те же возможности, что и покупатель «Single Family Home», а также те же права и обязанности. «Condo» может быть приобретено с помощью кредита. Купить квартиру гораздо выгоднее, чем дом, так как это гораздо дешевле. Цена начинается от восьмидесяти тысяч долларов, а при получении семидесяти процентов кредита, первоначальная выплата составит 30 процентов, т.е. примерно двадцать четыре тысячи долларов.

Из этого следует, что покупка «Condo» самый выгодный и перспективный вариант вложения при небольшом стартовом капитале. При этом последующая выгода может быть крайне значительной. Так, например пентхаусы в богатых района Лос-Анджелеса стоят около девяти миллионов долларов, а стоимость «Condo» в таких домах начинается с шестисот-семисот тысяч долларов. Такие квартиры можно купит в разных районах США - от самых простых до роскошных, что предоставляет для покупателя большой выбор цен и возможностей для дальнейшей прибыли. Важную роль при этом играет вид из окна квартиры. Если обычные дома в подавляющем большинстве трёхэтажные, то квартиру можно купить в высотном здании с панорамой гор, океана или города. При этом владелец не должен тратится на благоустройство территории дома, а ежедневная забота о доме, как например уборка мусора, охрана, чистка бассейна распределяется между всеми жильцами дома.

\section{Влияние ипотечного кризиса на рынок недвижимости США}

В 2007 завершился период «мыльного пузыря» и начался период кризиса. Начался он с коллапса старейшего инвестиционного банка Америки «Bears Stearns». Центральному Банку США пришлось дать вкладчикам гарантии на выплаты по долговым обязательствам от этого банка. В это же время стал рушиться кредитный рынок Америки, при этом больше всего пострадало ипотечные займы. Многим владельцам пришлось продавать своё жилье, так как процентные ставки были очень высоки и постоянно менялись. Предложение стало превышать спрос, из-за чего владельцам пришлось оставлять дома заемщикам в ходе процедуры «foreclosure» (потеря права выкупа).

Больше всего цены на недвижимость упали в следующих городах: Лас-Вегас, Невада, Майями, Флорида, Детройт, Мичиган, Феникс, Аризона и пять городов «золотого» штата Калифорния Риверсайд, Сан-Диего, Сакраменто, Анахайм и Лос-Анджелес,- а также флоридский Нэйпел. Причиной этого стал рост цен на жилье в последние несколько лет, который был вызван не в результате увеличения дохода от недвижимости, а благодаря спекуляциями на рынке недвижимости в этих штатах. Цены на дома в них падали до 2008 года, а стоимость потеряла от четырнадцати до двадцати процентов. Причиной падения стоимости жилья в Детройте был вызван сокращением населения, так как большое количество людей были уволены с автомобильных заводов «General Motors», «Ford» и «Chrysler».

Причиной роста цен не всегда являлись спекуляции. В Атланте наблюдался рост цен в результате увеличения населения. Начиная с сотой Олимпиады в Атланте (1966 г.) рынок недвижимости в этом штате стал развиваться стремительными темпами. При этом Атланта имела в своём активе аэропорт, благоприятный теплый климат, качественные дороги, высокий уровень жизни. Из-за этого ежегодно рост численности в этом штате увеличивался на сто пятьдесят тысяч человек, что является рекордным для штатов Америки. Несмотря на это, ипотечный кризис не обошёл стороной и этот процветающий город. Операции с переходом домов в собственность банков стали чаще всего производились именно здесь. При этом их продажа производилась значительно дешевле их реальной рыночной стоимости, доходя до сорока процентов.

Из-за кризиса и ужесточения условий выдачи ипотечных кредитов, под влияние падения стоимости и операций «foreclosures» попала и коммерческая недвижимость. Для коммерческой и жилой недвижимости существует различный порядок. Жилая чаще всего продаётся через единые региональные риэлтерские базы данных, а коммерческая недвижимость представлена в 
таких базах не полностью или даже вообще не попадает в них. Большинство хозяев продают коммерческую недвижимость частым инвесторам или инвестиционным фондам напрямую, без посредников. Сейчас самые актуальные и выгодные операции связаны с банковской коммерческой недвижимостью, которая носит название «commercial foreclosures». Этот тип недвижимости продается через представителей, ими выступают банки, в сферу специализации которых входит продажа банковской недвижимости.

При покупке недвижимости в США важно также помнить об ослабевающем положении доллара. Конечно, это выгодно для экономики США в рамках конкурентоспособности на общемировом рынке, но негативные стороны перевешивают положительные. Дешевый американский доллар является причиной повышения уровня инфляции, увеличения стоимости энергоносителей и уменьшение капитала. Поэтому дешевая валюта всё-таки несет в себе больше отрицательных сторон, чем положительных, что должно в будущем повысить стоимость доллара.

Однако, США не раз приходилось переживать экономические кризисы и выходить из них, поэтому ипотечный кризис - это лишь закономерная ступень развития, которая стала причиной финансовых неприятностей, но не сломила американскую экономику.

Поэтому недвижимость в США в любом случае остаётся привлекательной инвестицией. Многие иностранные инвесторы стали активно скупать жилье в надежде заработать на покупке дешевой недвижимости, чтобы в будущем иметь возможность как следует на ней заработать, так как усиление экономической ситуации было неизбежным.

\section{США}

Текущее состояние рынка недвижимости

В 2019 году экономика США развивалась стабильно и оптимистично. В течение всего года увеличивался рост рабочих мест и ВВП.

Федеральная резервная система (ФРС), выполняющая функции центрального банка, снизила процентные ставки по федеральным фондам в три раза. Эти показатели влияют на ставки по кредитам, таким как процент, выплачиваемый по ссуде на срок от одного до трёх лет. В ходе повышения ставок по федеральным фондам люди начинают больше откладывать и меньше тратить, что в результате приводит к торможению инфляции. Таким образом, за 2019 год понизился процент по федеральным фондам, а инфляция была ниже предполагаемых прогнозов экономистов.

При этом, если экономика США росла в 2019 году, то в других крупных странах она стала снижаться. В результате этого большинство американских компаний были вынуждены сократить расходы, так как нарастало напряжение с их торговыми партнёрами в других странах. Поэтому ФРС снизила ставку по федеральным фондам 3 раза, а также смягчило экономические требования к американским компаниям, что помогло им создать новые рабочие места и облегчить получение займов. Все эти меры помогли улучшить экономику США, несмотря на сложности.

Таким образом, низкие ставки по кредитам вызвали интерес у потенциальных покупателей к американской недвижимости и получению ипотеки. В 2019 году увеличилась доступность жилья, а количество домов на продажу снизилось.

За последние несколько лет цены на недвижимость США выросли, при этом количество жилья на продажу продолжало падать. Это вызвано рядом причин. Во-первых, из-за низких процентных ставок и растущей экономики увеличился спрос на покупку недвижимости. Во-вторых, после экономического кризиса строительство домов восстанавливается достаточно длительный период, что привело к нехватке жилых домов и квартир. Также спрос на покупку

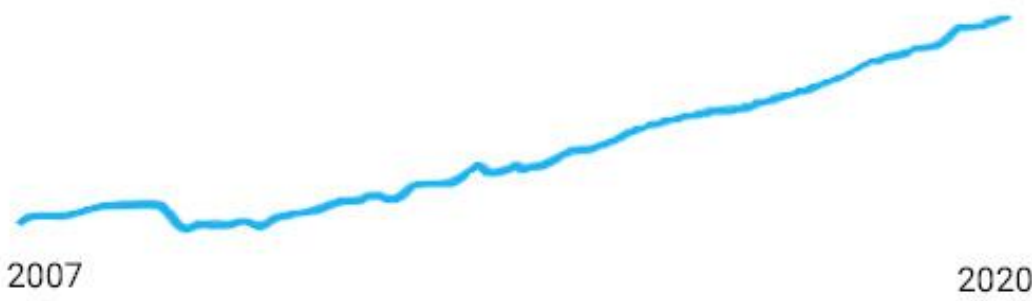

Рисунок 1. График роста заработной платы граждан США за 2007-2020 гг. 
недвижимости и уменьшение домов на продажу спровоцировал рост цен, из-за чего не все желающие могут позволить себе покупку жилья [1].

Рассмотрим статистические данные рынка недвижимости в Америке за 2020 год.

Размер жилищного фонда на начало июля составил 1,57 миллионов единиц, что выше на полтора процента, чем в мае, но меньше на восемнадцать процентов, чем в прошлом году. Непроданное жилье находится на уровне четырёхмесячного запаса при настоящих темпах продаж, по сравнению с показателями, зафиксированными в 2019 году. Шестьдесят два процента домов продавались меньше, чем за месяц.

Что касается покупателей, то около тридцати пяти процентов из них составили лица, которые приобретали жилье впервые. Процент вторичных покупателей составляет девять процентов от общего количества. Продажи за наличные составили шестнадцать процентов от суммы всех сделок.

Согласно данным крупнейшего ипотечного агентства Federal Home Loan Mortgage Corporation, годовая ставка за тридцать лет снизилась на 3,17\% в июне и с 3,2\% в мае. При этом в среднем уровень ставки ипотечного кредитования составил 3,95\% в 2019 году [2].

Продажи жилья на одну семью выросли до почти пяти миллионов в июне, при этом увеличились на $20 \%$ в мае и снизились на $10 \%$ по сравнению с 2019 годом.

Средняя стоимость жилья составляет двести девяносто восемь миллионов шестьсот тысяч долларов на одну семью, что больше на 3,5\% в сравнении с прошлым годом.

Также отдельно стоит отметить рост продаж кондоминиумов и кооперативов. Средняя стоимость квартир составляет двести шестьдесят две тысячи семьсот долларов, что больше на 1,5\%, чем в прошлом году.

Рассмотрим аналитические данные по различным регионам США в 2020 году. Так, на северо-востоке сделок стало больше на 4,3\%, с годовым показателем четыреста девяносто тысяч единиц. Это на 28\% меньше, чем летом 2019 года. Средняя цена при этом составила триста тридцать две тысячи девятьсот долларов, что на 3,5\% больше, чем в 2019 году.

На среднем западе продажи увеличились на $11 \%$ до отметки один миллион сто тысяч долларов объектов, что на тринадцать процентов меньше, чем в прошлом году. Средняя цена составила двести тридцать шесть тысяч девятьсот долларов, что на 3,2\% больше прошлогодних данных.

На юге страны рост сделок вырост на двадцать шесть процентов. Средняя цена зафиксирована на уровне двести пятьдесят восемь тысяч пятьсот долларов.

На Западе страны продажи на вторичном рынке недвижимости выросли на 32\% до годового уровня девятьсот пятьдесят тысяч долларов [3].

Также стоит отметить некоторые тенденции, с которыми столкнутся ипотечные заемщики, покупатели и продавцы жилья во второй половине 2020 года [4]:

1. Согласно прогнозам Freddie Мас, ставки по ипотечным кредитам должны были стабили-

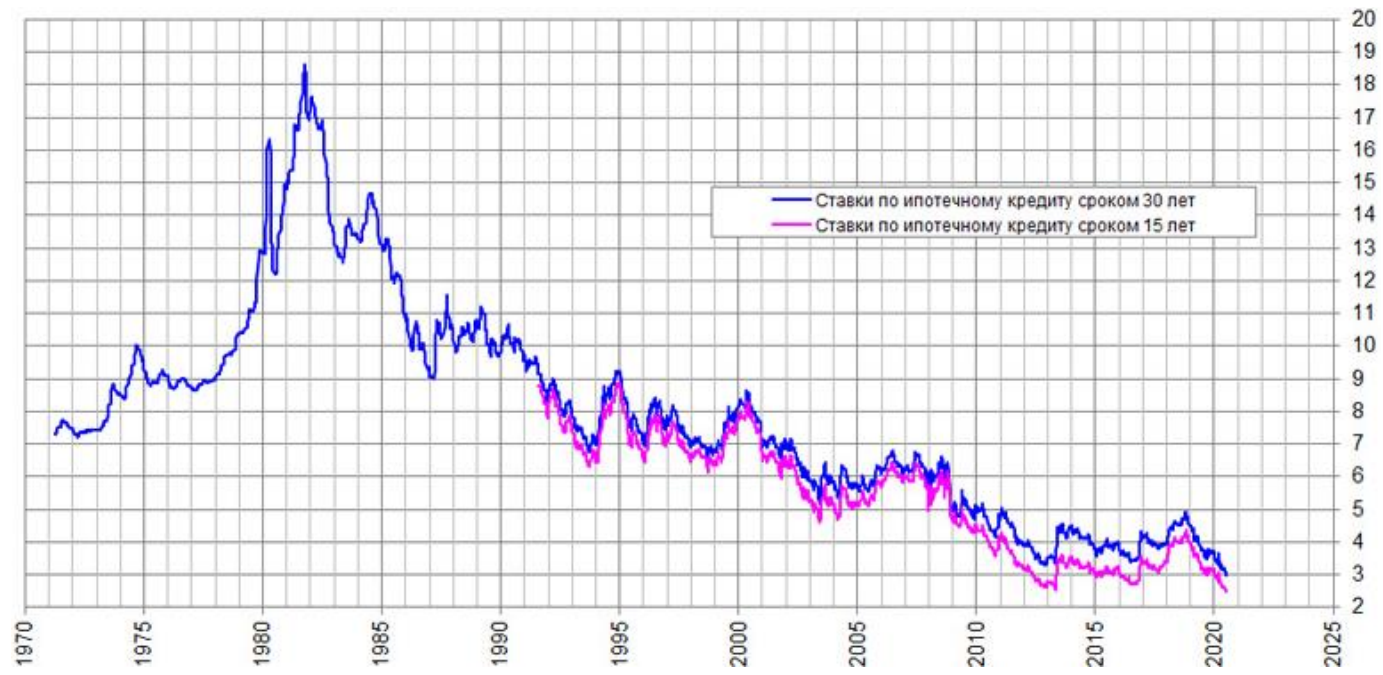

Рисунок 2. График ставок ставки ипотечного кредитования США 
зироваться и оставаться неизменными до конца 2020 года. Однако, вместо этого в феврале они значительно упали из-за ситуации с COVID-19. По данным ежедневного обзора процентных ставок по ипотечным кредитам американской финансовой компании «NerdWallet», средняя ставка по ипотечным кредитам упала почти на половину всего за 10 дней до 3,37\%. Но согласно экономическому анализу, Freddie Mac, MBA (Mortgage Bankers Association) и NAR (The National Association of Realtors) с октября по декабрь средняя ставка по ипотеке может составить около 3,25\% годовых и будет оставаться неизменной.

2. Возникнут сложности с покупкой нового жилья. Если COVID-19 продолжит распространяться, то продавцы не захотят сдавать или продавать свои дома потенциальным заемщика и покупателями, что снизит продажи в области недвижимости.

3. Снижение доступности жилья и рост цен на него. Лоуренс Юн, главный экономист NAR, сказал, что продажи домов должны вырасти с возобновлением экономического роста. Также он добавил, что строительство новых домов необходимо активно наращивать, чтобы удовлетворить растущий спрос на жилье. В противном случае цены на жилье будут расти слишком быстро и будут препятствовать новым покупателям, даже при рекордно низких ставках по ипотеке. Однако, нельзя забывать, что если владельцы в наиболее пострадавших районах не будут продавать свои дома в соображениях эпидемиологической безопасности, то маловероятно, что продажи домов могут вырасти в национальном масштабе. И хотя, согласно данным 15\% новых домов, проданных в мае 2020 года, стоили менее 200000 долларов по сравнению с 10\% в мае 2019 года, но при этом темпы ввода в эксплуатацию жилья замедлились из-за пандемии.

4. Бум рефинансирования. После того, как ставки по ипотечным кредитам упали, в феврале и марте ипотечная отрасль захлестнула волна рефинансирования. Кредиторы пережили период, когда у них было больше заявок на рефинансирование, чем они могли обработать. Они справились с нагрузкой, не снижая ставки настолько, насколько это возможно. Перспективы на оставшуюся часть 2020 года, согласно прогнозам американских экономистов следующие: волна рефинансирования достигла пика весной, следовательно, рефинансирование будет про- должать снижаться, даже если ставки упадут еще немного.

5. Отсутствие жилищной безопасности. Владельцы невидимости могут подать заявку на освобождение от ипотечного кредита до конца 2020 года. Но арендаторы уязвимы перед истечением моратория на выселение, что может привести к тому, что миллионы людей останутся без крова.

6. Рост популярности трехмерных домашних туров. Произошел скачок в использовании трехмерных туров по дому. Из-за запрета выходить на улицу продавцы домов не могли разрешить потенциальным покупателям посещать свои дома. Новые технологии позволили покупателям, которые тоже не горят желанием прогуливаться по чужим домам, виртуально посещать дома, используя технологию, аналогичную Street View. Популярность трехмерных домашних туров будет продолжать расти, поскольку они позволяют покупателям виртуально посещать несколько домов и сужать список домов для личного посещения.

Таким образом, подводя итоги экономической ситуации на рынке недвижимости в США за последние годы можно сделать следующие выводы:

- Сверхнизкие процентные ставки по ипотеке. В 2020 году низкие процентные ставки и снижение цен на жилье создают более доступные возможности для покупателей, которые мигрируют с дорогих городских рынков в пригородные районы средних городов. Однако предложение по-прежнему невелико, особенно для «домов для начинающих» с более низкими ценами, что означает, что продавцы могут требовать надбавку на многих рынках.

- Медленный рост цен на жилье. В апреле 2020 года цены на жилую недвижимость выросли на 0,6\% по сравнению с почти 4\%-ным ростом в марте. Но в течение третьей недели мая цены на жилье вернулись к темпам роста в $3 \%$. Постепенно цены возвращаются к уровню до пандемии.

- Положительная динамика роста. В целом на рынке присутствуют благоприятные условия для развития. В то время как позитивные тенденции в безработице и экономическом росте за последний год всегда могут быть обращены вспять, многие симптомы, которые привели к крупному краху рынка жилья в 2008 году, сегодня отсутствуют. 


\section{Библиографический список}

1. Новые тенденции на рынке недвижимости 2020 // PWC URL: https://www.pwc.ru/ru/ publications/etre/etre-2020.pdf (дата обращения: 29.09.2020).

2. Новые тренды на глобальном рынке недвижимости // konkurent.ru URL: https://konkurent. ru/article/25586 (дата обращения: 29.09.2020).

$3 . \quad$ Рынок коммерческой недвижимости США восстанавливается хуже жилого сектора // homesoversea URL: https://www.homesoverseas.ru/news/Rynok_kommercheskoj_nedvizhimosti_SShA_ vosstanavlivaetsja_huzhe_zhilogo_sektora (дата обращения: 29.09.2020).

4. Рынок недвижимости США: июнь 2020 // Деловой журнал URL: https://delovoyjournal.com/ rynok-nedvizhimosti-ssha-ijun-2020/ (дата обращения: 29.09.2020).

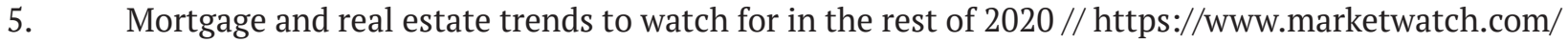
URL: https://www.marketwatch.com/story/mortgage-and-real-estate-trends-to-watch-for-in-the-restof-2020-2020-07-27 (дата обращения: 29.09.2020). 